\title{
Desempenho de Novilhas Mestiças e Parâmetros Ruminais em Novilhos, Suplementados durante o Período das Águas 1
}

\section{Joanis Tilemahos Zervoudakis², Mário Fonseca Paulino ${ }^{3}$, Edenio Detmann ${ }^{4}$, Sebastião de Campos Valadares Filho ${ }^{3}$, Rogério de Paula Lana ${ }^{3}$, Paulo Roberto Cecon ${ }^{5}$}

\begin{abstract}
RESUMO - Foram utilizadas 21 novilhas mestiças Holandês-Zebu, com idade e pesos médios iniciais de 14 meses e $245 \mathrm{~kg}$, respectivamente, para avaliação do desempenho. Para avaliação dos parâmetros ruminais e amostragem do pasto consumido, utilizaram-se cinco novilhos Limousin x Nelore, fistulados no rúmen e esôfago, mantidos em pastagem à parte de Brachiaria brizantha cv. Marandu. O experimento foi conduzido em três períodos experimentais, segundo um delineamento inteiramente casualizado. Foram fornecidos sal mineral (SAL), suplementos à base de milho e farelo de glúten de milho (MFGM) e milho e farelo de soja (MFS), fornecidos em nível de 0,5 kg/animal, diariamente às $10 \mathrm{~h}$. Houve efeito da suplementação sobre o desempenho das novilhas. Os animais alimentados com suplementos MFS e MFGM foram semelhantes e superiores, respectivamente, aos do tratamento SAL, sendo que os ganhos médios diários foram, respectivamente, de 0,920; 0,883; e $0,708 \mathrm{~kg} /$ animal. A análise de pH ruminal demonstrou efeito para suplementos, tempo de coleta e interação suplemento e tempo. $\mathrm{Na}$ análise da concentração de amônia ruminal, observaram-se diferenças entre tratamentos e interação tempo de coleta $\mathrm{x}$ tratamento. As concentrações de amônia ruminal dos bovinos submetidos ao tratamento com proteína degradável no rúmen (MFS) foram, em média, 23 e 30\% superiores às concentrações de amônia dos bovinos nos tratamentos testemunha (SAL) e proteína não-degradável no rúmen (MFGM), respectivamente. Os valores de pH e concentração de amônia ruminal, apesar de terem sido influenciados pela suplementação e alterados em função dos tempos de coleta, mantiveram-se em magnitude adequada para digestão e fermentação ruminal da fibra.
\end{abstract}

Palavras-chave: suplementos, pastagens, pH, amônia

\section{Performance and Ruminal Characteristics of Crossbred Yearling Heifers Supplemented during the Rainy Season}

ABSTRACT - Twenty one crossbred yearlings Holstein-Zebu heifers, with average initial age and weights of 14 months and $245 \mathrm{~kg}$, respectively, were used in the performance evaluation. For evaluation of the ruminal parameters and sampling of the consumed pasture, five Limousin x Nelore steers, fistulated in the rumen and esophagus and maintained in an extra pasture of Brachiaria brizantha cv. Marandu, were used to evaluate ruminal parameters, pasture intake and to collect pasture samples. The experiment was carried out during three experimental periods, according to a complete randomized design. The following supplements, daily fed at 10 a.m., were used: mineral salt (SALT), supplements based on corn and corn gluten meal (CMCG) and corn and soybean meal (CSBM), supplied at the level of $0.5 \mathrm{~kg} /$ animal. There was supplementation effect on the performance of the yearlings heifers. The animals fed CSBM and CMCG were similar and superior than the animals fed SALT, and the average daily gain were, respectively, $0.920,0.883$, and $0.708 \mathrm{~kg} / \mathrm{animal}$. There were effects of supplementation, collection time and interaction between supplement and time on ruminal $\mathrm{pH}$, and supplementation and interaction between supplement and time on ruminal ammonia. The ruminal ammonia concentrations of the steers submitted to the treatment with ruminal degradable protein (CSBM) were 23 and 30\% superior, in the average, than the control (SALT) and ruminal undegradable protein $(\mathrm{CMCG})$ treatments, respectively. The $\mathrm{pH}$ values and ruminal ammonia concentration, although influenced by supplementation and altered in function of times of collect, kept at adequate levels for ruminal fiber digestion and fermentation.

Key Words: supplements, pastures, pH, ammonia

\footnotetext{
1 Parte da tese do primeiro autor, apresentada à Univ. Fed. de Viçosa, para obtenção do título de Magister Scientiae em Zootecnia 2 Zootecnista, MS, Estudante de Doutorado, DZO-UFV, Viçosa-MG, 36571-0000. E.mail: joanis@alunos.ufv.br

3 Professor do Departamento de Zootecnia, Universidade Federal de Viçosa, Pesquisador do CNPq, Viçosa-MG, 36571-000.

4 Zootecnista, DS, LEAG - UENF, Campos dos Goytacazes, RJ. E.mail: detmann@globo.com

${ }^{5}$ Professor do Departamento de Informática, Universidade Federal de Viçosa, Viçosa-MG, 36571-000.
} 


\section{Introdução}

Nos rebanhos de corte, alterações no ritmo de crescimento dos animais jovens modificam o ciclo produtivoe, conseqüentemente, promovem melhorias consideráveis na eficiência de exploração de bovinos destinados ao abate.

Entretanto, verifica-se que a produção de carne depende não somente dos animais destinados ao abate, mas também das matrizes, dos reprodutores e das novilhas de reposição, as quais, ao serem desmamadas com cerca de $180 \mathrm{~kg}$, devem ser alimentadas para ganhar em torno de 0,3 a $0,5 \mathrm{~kg}$ por dia e, portanto, consumir diariamente cerca de 5,5 a $6,0 \mathrm{~kg}$ de MS (Peixoto, 1993).

Com relação à estrutura produtora de carne, verifica-se que a fase de recria reúne o maior grupo de bovinos $(48,2 \%)$, seguida das fases de cria $(40,4 \%)$ e engorda $(11,4 \%)$. Além disso, a fase de recria retém os bovinos por longo período (entre 12 e 36 meses), de forma a constituir $58,3 \%$ do ciclo de produção, seguida das fases de cria $(16,7 \%)$ e engorda $(25,0 \%)$. Em função deste alto contingente populacional e da prolongada duração desta fase, a recria contribui de forma negativa para a eficiência do processo produtivo como um todo (Villares, 1984).

Sendo as pastagens a base da alimentação de rebanhos estabelecidos nas regiões tropicais, da interação existente entre as exigências nutricionais e o valor nutritivo da pastagem, obtém-se o desempenho animal, o qual pode ser satisfatório ou não. Frente a um desempenho não-satisfatório, há necessidade de se promover a suplementação dos animais, a qual deve ser conveniente do ponto de vista técnico-econômico (Andrade, 1993).

Contudo, um dos fatores preponderantes com relação à produção de animais em sistema de suplementação a pasto consiste na definição dos objetivos principais desta suplementação dentro do sistema de produção existente. Conseqüentemente, devem-se estabelecer estratégias de fornecimento de nutrientes que viabilizem, da melhor forma possível, os padrões de crescimento estabelecidos pelo sistema de produção (P aulino, 1998). Nesse contexto, o fornecimento de nutrientes via suplementação pode ensejar ganhos diferenciados de desempenho dos animais, objetivando mantença de peso, ganhos moderados diários de aproximadamente 200-300 g/animal ou até mesmo ganhos de 500-600 g/animal/dia, quando se pretende cobrir fêmeas com 15 meses ou abater machos aos 20-24 meses de idade, para produção do novilho precoce.
A utilização de fontes protéicas de baixa degradabilidade ruminal (proteína de escape), em programas de suplementação a pasto, é importante, quando a disponibilidade da forragem é alta, mas o seu conteúdo em proteína bruta é baixo. Igualmente, quando os animais estão em déficit energético, devido à baixa oferta de forragem, ou a exigência excede $o$ nível de consumo de energia, a suplementação de fontes de baixa degradabilidade ruminal surge como alternativa para a obtenção de ganhos maiores por bovinos em pastejo (Reis et al., 1997).

Verifica-se que animais em pastejo, durante a estação chuvosa, respondem a aumento no fornecimento de proteína intestinal (Poppi \& McLennan, 1995). Entretanto, se o suplemento possuir significante quantidade de energia disponível, como no caso do farelo de algodão, a resposta pode não ocorrer, possivelmente devido ao efeito substitutivo que se fará presente notadamente quando a forragem consumida for de alta qualidade.

Objetivou-se, com o presente estudo, avaliar o efeito da suplementação com fontes de proteína degradada e não-degradada no rúmen sobre o desempenho de novilhas mestiças Holandês-Zebu recriadas em sistema de pastejo, no período das águas, e os parâmetros ruminais de novilhos, recebendo tratamentos semelhantes.

\section{Material e Métodos}

A área experimental constituiu-se de três piquetes de Brachiaria brizantha cv. Marandu, providos de bebedouro e comedouro coberto, mantendo-se taxa de lotação de 1,5 U.A./ha. Os animais foram rotacionados entre os piquetes a cada 28 dias.

Foram utilizadas 21 novilhas mestiças HolandêsZebu, com idade e peso médios iniciais de 14 meses e $245 \mathrm{~kg}$, respectivamente, e escolhidas em função do grau de sangue, da idade e do peso.

Os animais foram pesados no início e no final de cada período experimental. O experimento foi conduzido no período de janeiro a maio de 1998, durante o período chuvoso.

Os animais foram distribuídos em três lotes uniformes, quanto ao peso vivo e à condição corporal, e, posteriormente, designados, aleatoriamente, aos seguintes tratamentos:

T1 - controle, sem suplementação (SAL);

T2 - suplemento constituído de milho e farelo de glúten de milho $(0,5 \mathrm{~kg} /$ dia $)(\mathrm{MFGM})$; e 
T3 - suplemento constituído de milho e farelo de soja $(0,5 \mathrm{~kg} / \mathrm{dia})$ (MFS).

Os suplementos foram previamente balanceados, em função dos valores de composição relatados por Campos (1995), objetivando atingir nível de 40\% de proteína bruta, com base na matéria natural (Tabela 1), sendo fornecidos diariamente aos animais às $10 \mathrm{~h}$.

Amostras representativas de todos os suplementos foram coletadas a cada preparo das misturas, homogeneizadas para obtenção da amostra composta de todo o período experimental e, posteriormente, armazenadas para análises laboratoriais.

A determinação da disponibilidade e amostragem da Brachiaria brizantha cv. Marandu foi realizada conforme descrito por McMeniman (1997), posteriormente as amostras foram pesadas, homogeneizadas e reunidas em amostras compostas por piquete, as quais foram identificadas, armazenadas e congeladas para posterior cálculo da disponibilidade de matéria seca por hectare (MS/ha) e composição bromatológica da pastagem.

Para se amostrar o pasto consumido em cada período experimental, foram utilizados três novilhos $1 / 2$ sangue Limousin $x$ Nelore, castrados, com idade e

Tabela 1 - Proporção dos ingredientes nos suplementos, expresso na base da matéria natural

Table 1 - Proportion of ingredients in the supplements expressed in natural matter

\begin{tabular}{|c|c|c|c|}
\hline \multirow[b]{2}{*}{$\begin{array}{l}\text { Componente } \\
\text { Component }\end{array}$} & \multicolumn{3}{|c|}{$\begin{array}{c}\text { Tratamento } \\
\text { Treatment }\end{array}$} \\
\hline & $\begin{array}{l}\mathrm{SAL}^{2} \\
\text { Salt }\end{array}$ & $\begin{array}{r}\text { MFGM } \\
C M C G\end{array}$ & $\begin{array}{l}\text { MFS } \\
C S B M\end{array}$ \\
\hline $\begin{array}{l}\text { Mistura mineral } \\
\text { Mineral premix }\end{array}$ & 100,0 & - & - \\
\hline $\begin{array}{l}\text { Milho grão } \\
\text { Corn grain }\end{array}$ & - & 57,7 & 40,5 \\
\hline $\begin{array}{l}\text { Farelo de glúten milho } \\
\text { Corn gluten meal }\end{array}$ & - & 42,3 & - \\
\hline $\begin{array}{l}\text { Farelo de soja } \\
\text { Soybean meal }\end{array}$ & - & - & 59,5 \\
\hline $\begin{array}{l}{ }^{1} \text { Composição percentual } \\
\text { sódio, } 48,01 \text {; sulfato de } \\
\text { sulfato de cobalto, } 0,05 \text {; } \\
2 \text { SAL: mistura mineral. } \\
\text { MFS: suplemento à base } \\
\text { MFGM: suplemento à ba } \\
1 \text { Percentual composition: dic } \\
\text { 48.01; zinc sulfate, } 1.50 ; \text { co } \\
\text { potassium iodate, } 0.03 \text {. } \\
{ }^{2} \text { Salt: mineral salt. } \\
\text { CSBM: supplement based of } \\
\text { CMGM: supplement based o }\end{array}$ & $\begin{array}{l}\text { fosfato } \\
\text { zinco, } 1, \\
\text { iodato } \\
\text { de milho } \\
\text { de milho } \\
\text { berium pho } \\
\text { per sulfate }\end{array}$ & $\begin{array}{l}\text { co, } 50,0 \\
\text { ulfato de } \\
\text { ássio, } 0, \\
\text { lo de so } \\
\text { elo de glu } \\
50.01 ; \text { so } \\
\text { cobalt su } \\
\text { n meal. } \\
\text { luten meal }\end{array}$ & $\begin{array}{l}\text { oreto de } \\
\text { re, } 0,40 \text {; } \\
\text { de milho. } \\
\text { chloride, } \\
0.05 \text {; and }\end{array}$ \\
\hline
\end{tabular}

R. Bras.Zootec., v.31, n.2, p.1052-1058, 2002 (suplemento) peso médios iniciais de 22 meses e $396 \mathrm{~kg}$, respectivamente, fistulados no esôfago e rúmen, os quais foram mantidos em área anexa de Brachiaria brizantha cv. Marandu, durante o mesmo período experimental, e levados para os piquetes experimentais, nos dias de amostragem do pasto consumido pelos animais.

No dia anterior às amostragens de extrusa, às $19 \mathrm{~h}$, os novilhos foram recolhidos ao curral, a fim de se propiciar um período de jejum de sólidos de, aproximadamente, 12 horas. Em cada dia de amostragem, às $7 \mathrm{~h}$, foram removidas as cânulas esofágicas dos animais e colocadas as bolsas coletoras. Posteriormente, cada animal foi conduzido a um dos três piquetes experimentais para pastejar durante 40-50 minutos, com o mínimo de perturbação possível, para não interferir no comportamento de pastejo dos animais (Sanches et al., 1993). Em seguida, os animais foram contidos para retirada das bolsas coletoras e colocação das cânulas esofágicas, sendo, posteriormente, soltos para pastejar normalmente.

As amostras coletadas, representativas de cada piquete experimental, foram congeladas, para posteriores processamento e análises laboratoriais.

Para determinação do consumo, utilizaram-se cinco novilhos $1 / 2$ sangue Limousin $x$ Nelore, castrados, fistulados no esôfago e rúmen, os quais foram mantidos em área anexa de Brachiaria brizantha cv. Marandu. O consumo de MS foi determinado utilizando-se o óxido crômico como indicador externo, aplicado em uma dose diária de $20 \mathrm{~g}$, dividida em duas aplicações diárias de $10 \mathrm{~g}$, administradas às $8 \mathrm{e}$ $17 \mathrm{~h}$, acondicionadas em cartucho de papel e aplicadas diretamente no rúmen por intermédio da fístula ruminal. Como indicador interno, utilizou-se a fibra em detegente neutro indigestível (FDNi).

Na determinação da produção de matéria seca fecal, os animais receberam uma aplicação diária de $20 \mathrm{~g}$ de óxido crômico, durante um período de adaptação de sete dias; a partir do oitavo até o décimo terceiro dia, foram realizadas coletas de fezes diretamente no reto, junto com a aplicação de óxido crômico.

As amostras fecais, após secas e moídas, foram compostas proporcionalmente por tratamento e período. Nas determinações de cromo utilizou-se espectrofotômetria de absorção atômica, segundo a técnica descrita por Willians et al. (1962).

Para as estimativas de consumo a partir da FDNi, adotou-se procedimento único, seqüencial, adaptando-se as técnicas descritas por Penning \& Johnson (1983) e Cochran et al. (1986). 
Na determinação do consumo, utilizaram-se as seguintes fórmulas: Excreção fecal $(\mathrm{EF})(\mathrm{g} / \mathrm{dia})=\frac{\text { Óxido crômico fornecido }(\mathrm{g} / \mathrm{dia})}{\text { Concentração óxido crômico }}$ nas fezes (g/gMS)

Consumo MS $(\mathrm{kg} / \mathrm{dia})=\mathrm{EF}(\mathrm{kg} / \mathrm{dia}) \times$ Concentração FDNi nas fezes Concentração FDNi na extrusa

As amostras de forragem provenientes das coletas de extrusa e as amostras de fezes foram secas em e stufa ventilada a $65^{\circ} \mathrm{C}$, processadas em moinho do tipo Willey, em peneira de $1 \mathrm{~mm}$ e os teores de matéria seca (MS), proteína bruta (PB), cinzas, extrato etéreo (EE), magnésio $(\mathrm{Mg})$, cálcio $(\mathrm{Ca})$, fósforo $(\mathrm{P})$ e potássio $(\mathrm{K})$ foram determinados conforme procedimentos descrito por Silva (1990). A determinação dos teores de fibra em detergente neutro (FDN) foi feita segundo técnica descrita por Van Soest et al. (1991). Os carboidratos totais (CHOT) foram obtidos por intermédio da equação: $100-(\% \mathrm{~PB}+\% \mathrm{EE}+\%$ Cinzas $)$ e os carboidratos não-estruturais (CNE), pela diferença entre CHOT e FDN (Sniffen et al., 1992).

A composição bromatológica da extrusa encontra-se na Tabela 2.

As coletas de líquido ruminal para determinação do $\mathrm{pH}$ e das concentrações de $\mathrm{N}-\mathrm{NH}_{3}$ foram realizadas imediatamente antes do fornecimento do suplemento e 2, 4 e 6 horas após, utilizando-se novilhos 1/2 sangue Limousin $\mathrm{x}$ Nelore, castrados, fistulados no rúmen. Foram coletados aproximadamente $40 \mathrm{~mL}$ de líquido ruminal, procedendo-se imediata determinação do $\mathrm{pH}$, em peagâmetro digital.

Após a leitura do $\mathrm{pH}$, adicionou-se a cada amostra $1 \mathrm{~mL}$ de solução de $\mathrm{HCl}$ 1:1; que foi armazenada a $20^{\circ} \mathrm{C}$ para posterior determinação das concentrações de $\mathrm{N}-\mathrm{NH}_{3}$. As concentrações de $\mathrm{N}-\mathrm{NH}_{3}$ nas amostras do líquido ruminal filtrado foram determinados mediante destilação com Hidróxido de Potássio 2N.

Para análise dos valores de $\mathrm{pH}$ e amônia, procedeu-se à subdivisão em função do tempo de coleta, segundo o modelo:

$$
\hat{Y}_{\mathrm{ijk}}=\mu+\mathrm{t}_{\mathrm{i}}+\mathrm{b}_{\mathrm{j}}+\mathrm{tb}_{\mathrm{ij}}+\mathrm{t}_{\mathrm{k}}^{\prime}+\mathrm{tt}_{\mathrm{ik}}^{\prime}+\mathrm{e}_{\mathrm{ijk}}
$$

em que: $\hat{Y}_{\mathrm{ijk}}=$ valor observado relativo ao suplemento $\mathrm{i}$, no animal $\mathrm{j}$ e no tempo $\mathrm{k} ; \mu=$ média geral; $\mathrm{t}_{\mathrm{i}}=$ efeito do suplemento $\mathrm{i}$, sendo $\mathrm{i}=1,2$ e $3 ; \mathrm{b}_{\mathrm{j}}=$ efeito do animal ou bloco $\mathrm{j}$, sendo $\mathrm{j}=1,2,3,4$ e 5 ; $\mathrm{tb}_{\mathrm{ij}}=$ efeito residual das parcelas; $\mathrm{t}_{\mathrm{k}}=$ efeito do tempo $\mathrm{k}$, sendo
Tabela 2 - Teores médios de matéria seca (MS\%), matéria orgânica (MO), proteína bruta (PB), extrato etéreo (EE), carboidratos totais (CHOT), fibra em detergente neutro (FDN), carboidratos nãoestruturais (CNE), cinzas, magnésio (Mg), cálcio $(\mathrm{Ca})$, fósforo $(\mathrm{P})$ e potássio $(K)$, da extrusa, nos diferentes períodos experimentais

Table 2 - Average content of dry matter (DM), organic matter $(O M)$, crude protein $(C P)$, ether extract $(E E)$, total carbohydrate (TC), neutral detergent fiber (NDF), non- structural carbohydrate (NSC), ash, $\mathrm{Mg}, \mathrm{Ca}$, $P$ and $K$, for extrusa at different experimental periods

\begin{tabular}{lccc}
\hline & \multicolumn{3}{c}{$\begin{array}{c}\text { Extrusa } \\
\text { Extrusa }\end{array}$} \\
\cline { 2 - 4 } Itens & $\begin{array}{c}\text { Período } \\
\text { Period 1 }\end{array}$ & $\begin{array}{c}\text { Período 2 } \\
\text { Period 2 }\end{array}$ & $\begin{array}{c}\text { Período 3 } \\
\text { Period 3 }\end{array}$ \\
\hline MS $(D M) \%$ & 15,7 & 12,1 & 14,7 \\
MO $(O M)^{1}$ & 91,2 & 89,8 & 90,3 \\
PB $(C P)^{1}$ & 10,2 & 11,8 & 8,1 \\
EE $(E E)^{1}$ & 0,6 & 0,7 & 1,1 \\
CHOT $(T C)^{1}$ & 80,4 & 77,2 & 81,1 \\
FDN $(N D F)^{1}$ & 72,5 & 73,3 & 70,4 \\
CNE $(C N S)^{1}$ & 7,9 & 3,9 & 10,7 \\
Cinzas $(A s h)^{1}$ & 8,8 & 10,2 & 9,7 \\
Mg $^{1}$ & 0,11 & 0,14 & 0,12 \\
Ca $^{1}$ & 0,17 & 0,32 & 0,22 \\
$\mathrm{P}^{1}$ & 0,13 & 0,17 & 0,15 \\
$\mathrm{~K}^{1}$ & 0,65 & 1,36 & 1,15 \\
\hline 1
\end{tabular}

$1 \% \mathrm{MS}(\% \mathrm{DM})$.

${ }^{2}$ Período 1: 10 de janeiro a 7 de fevereiro de 1998.

Período 2: 8 de fevereiro a 8 de março de 1998.

Período 3: 9 de março a 7 de abril de 1998.

Period 1: from January 10 to February 7 of 1998.

Period 2: from February 8 to March 8 of 1998.

Period 3: from March 8 to April 7 of 1998.

$\mathrm{k}=1,2,3$ e 4; $\mathrm{tt}^{\prime}{ }_{\mathrm{ik}}=$ efeito da interação do i-ésimo nível do suplemento $\mathrm{t}$, com o k-ésimo nível do tempo k; e $e_{i j k}=$ erro aleatório, associado a cada observação.

Para determinação do desempenho, foi conduzido um delineamento inteiramente casualizado, segundo o modelo:

$$
\hat{Y}_{\mathrm{ij}}=\mu+\mathrm{t}_{\mathrm{i}}+\mathrm{e}_{\mathrm{ij}}
$$

em que: $\hat{Y}_{\mathrm{ij}}=$ valor observado na unidade experimental que recebeu o suplemento $i$ na repetição $j$; $\mu=$ média geral; $\mathrm{t}_{\mathrm{i}}=$ efeito do suplemento $\mathrm{i}$, sendo $\mathrm{i}=1,2,3,4$ e $5 ; \mathrm{j}=1,2,3,4,5 \ldots .7 ; \mathrm{e} \mathrm{e}_{\mathrm{ij}}=$ erro aleatório, associado a cada observação.

Para realização das comparações entre médias, adotou-se o teste de Newman Keulls, sendo que todas as análises foram realizadas por intermédio do programa SAEG (Universidade Federal de Viçosa - UFV, 1995), adotando-se o nível de significância de 5\%. 


\section{Resultados e Discussão}

Os resultados referentes ao desempenho das novilhas estão apresentados na Tabela 3. Como pode ser verificado, os animais que receberam somente sal mineral apresentaram menores $(\mathrm{P}<0,05)$ peso vivo final e ganhos médios total e diário.

Resultados contrários ao deste estudo foram encontrados por Elizalde et al. (1998), que, avaliando o efeito de diferentes níveis de proteína e energia na suplementação de novilhos em pastejo, não encontraram diferenças expressivas no desempenho dos animais, para os diferentes suplementos, em relação ao tratamento testemunha.

Os ganhos médios diários (GMD) obtidos por Elizalde et al. (1998), em novilhos consumindo 1,4 kg de milho quebrado $(0,77 \mathrm{~kg} / \mathrm{dia})$ e $1,4 \mathrm{~kg}$ de farelo de glúten de milho $(0,69 \mathrm{~kg} / \mathrm{dia})$, foram inferiores aos obtidos neste estudo, que foram de 0,88 e $0,92 \mathrm{~kg} / \mathrm{dia}$, respectivamente, para os tratamentos MFGM e MFS, fornecidos na base de $0,5 \mathrm{~kg} / \mathrm{dia}$. A menor eficiência alimentar obtida por Elizalde et al. (1998), os quais forneceram quantidades de suplemento superiores às deste estudo, possivelmente deve-se às altas taxas de substituição verificadas para os tratamentos com milho quebrado e farelo de glúten de milho $(0,78$ e $0,63 \mathrm{~g}$ de forragem/g de suplemento), indicando, dessa forma, que os animais reduziram o consumo de forragem, em razão do alto consumo dos suplementos.

Resultados contraditórios têm sido obtidos em estudos avaliando o fornecimento de fontes de proteína não-degradada (PNDR) e degradada no rúmen
(PDR). Em experimento avaliando os efeitos de diferentes suplementos protéicos no desempenho e na eficiência alimentar de novilhas Holandesas em confinamento, Coomer et al. (1993) verificaram superioridade no GMD dos animais submetidos aos tratamentos com proteína não-degradada no rúmen (PNDR), proveniente do farelo de soja tostado e farelo de glúten de milho, quando comparados aos animais do tratamento com proteína degradada no rúmen (PDR), proveniente do farelo de soja. De acordo com Coomer et al. (1993), devido à redução na digestão ruminal da matéria orgânica (MO) e ao aumento no fluxo de proteína bruta (PB) bacteriana para o abomaso, a eficiência de síntese de PB bacteriana foi maior nos bovinos alimentados com PNDR (16,2 g PB bacteriana/100 g MO aparentemente digerida) que nos bovinos com PDR (9,7 g PB bacteriana/100 g MO aparentemente digerida).

Os consumos de PNDR no presente estudo, com base em valores tabelados e nas quantidades fornecidas, foram de 288 e $216 \mathrm{~g} / \mathrm{dia}$, respectivamente, para os tratamentos MFGM e MFS. O NRC (1989) recomenda, para novilhas em crescimento com $245 \mathrm{~kg}$ e ganho médio diário em torno de $700 \mathrm{~g} / \mathrm{dia}$, requerimento de 249 g/dia de PNDR. Esses dados indicam que ambos os suplementos proporcionaram suficiente PNDR para obtenção de adequadas taxas de crescimento. Entretanto, verifica-se que a maior quantidade de PNDR no suplemento MFGM não proporcionou aos animais submetidos a este tratamento maior desempenho em relação aos do tratamento MFS.

Tabela 3 - Médias para peso vivo inicial (PVJI) e final (PVJF), ganhos de peso total (GDP) e diário (GMD), em função dos tratamentos

Table 3 - Means for initial (LWFI) and final live weight (LWFF), total (TG) and average daily gain (ADG), according to the treatments

\begin{tabular}{lccccc}
\hline Itens & \multicolumn{5}{c}{$\begin{array}{c}\text { Tratamento } \\
\text { Treatment }\end{array}$} \\
\cline { 2 - 4 } & $\mathrm{SAL}^{2}$ & MFGM & MFS & Média & CV \\
& Salt & $C M C G$ & $C M C S$ & Mean & 13,47 \\
PVJI $(L W F I), \mathrm{kg}^{1}$ & 263,1 & 265,0 & 266,4 & 264,9 & 13,33 \\
PVJF $(L W F F), \mathrm{kg}^{1}$ & $343,9^{\mathrm{B}}$ & $365,7^{\mathrm{A}}$ & $371,9^{\mathrm{A}}$ & 360,5 & 16,96 \\
$\operatorname{GDP}(T G), \mathrm{kg}^{1}$ & $80,7^{\mathrm{B}}$ & $100,7^{\mathrm{A}}$ & $105,5^{\mathrm{A}}$ & 95,6 & 16,97 \\
GMD $(A D G), \mathrm{kg}^{1}$ & $0,708^{\mathrm{B}}$ & $0,883^{\mathrm{A}}$ & $0,920^{\mathrm{A}}$ & 0,838 & \\
\hline
\end{tabular}

1 Médias na linha, seguidas por letras diferentes, são diferentes $(P<0,05)$ pelo teste de Newman keuls.

2 Sal: mistura mineral.

MFGM: suplemento à base de milho e farelo de glúten de milho.

MFS: suplemento à base de milho e farelo de soja.

${ }^{1}$ Means, within a row, followed by different letters are different $(P<.05)$ by Newman Keuls test.

2 Salt: mineral salt.

CMGM: supplement based on corn and corn gluten meal.

CSBM: supplement based on corn and soybean meal.

\section{R. Bras.Zootec., v.31, n.2, p.1052-1058, 2002 (suplemento)}


Adicionalmente, os suplementos do presente estudo foram formulados para conter $40 \%$ de PB, porém revelaram média de 35,29 e 43,28\% de PB, para os tratamentos MFGM e MFS, respectivamente. Dessa forma, com o consumo de matéria seca proveniente da pastagem de $1,96 \%( \pm 10,24)$ do peso vivo ou $4,82 \mathrm{~kg} / \mathrm{dia}$, somado ao consumo de proteína bruta dos suplementos, verifica-se consumo total de PB de 0,684 kg proteína/dia, suficiente para assegurar adequado suprimento de proteína, permitindo, assim, que os animais atendessem seus requerimentos de aminoácidos para crescimento.

O fornecimento do farelo de soja + milho (PDR) permitiu GMD das novilhas superiores em $30 \%$ (212 g/dia), em relação ao tratamento testemunha (sal mineral), tal fato pode ser devido ao maior consumo de proteína e a maior proporção de amônia ruminal, a qual proporcionou maior digestão da forragem pelos microrganismos ruminais, propiciando consequentemente maior consumo de forragem pelos animais suplementados, quando comparados aos animais testemunha.

Suplementando novilhas em pastagens com teor protéico semelhante ao do presente estudo, Hafley et al. (1993) verificaram GMD superiores dos animais submetidos ao suplemento com PDR (1030 g/dia) em relação aos com PNDR (970g/dia).

Na Tabela 4 são apresentados os custos dos suplementos e os ganhos médios diários excedentes por animal em relação ao tratamento controle (SAL). Ao considerar-se os ganhos numéricos obtidos em cada tratamento, observou-se maior retorno com a utilização da fonte protéica farelo de soja, visto que apresentou ganho levemente superior aos tratamento MFGM, embora sem diferença significativa $(\mathrm{P}>0,05)$.

De outra forma, ao considerar-se estritamente o resultado apontado pela análise estatística dos dados, ou seja, assumindo-se média de ganho comum aos tratamentos em que se empregou suplementação, uma vez não sendo encontradas diferenças significativas $(\mathrm{P}>0,05)(0,194 \mathrm{~kg} / \mathrm{dia})$, observou-se manutenção do comportamento mostrado anteriormente (Tabela 4), com superioridade em retorno econômico para o tratamento MFS, reflexo direto do menor custo deste suplemento em relação a MFGM.

Ressalta-se, que variações no retorno econômico refletem-se diretamente em condições regionais e período do ano em que os alimentos são adquiridos, frisando-seque a avaliação econômica mostrada neste trabalho assume características particulares e circunstanciais.
Tabela 4 - Custos de suplementos e ganho médio diário excedente ao tratamento controle (SAL), para os diferentes tratamentos

Table 4 - Supplements costs and spare average daily gain to control treatment (SAL), according to the treatments

\begin{tabular}{|c|c|c|}
\hline & \multicolumn{2}{|c|}{$\begin{array}{c}\text { Tratamento } \\
\text { Treatment }\end{array}$} \\
\hline & MFGM & MFS \\
\hline \multicolumn{3}{|c|}{ Custo do suplemento (CS) ${ }^{1}$} \\
\hline \multicolumn{3}{|l|}{ Supplement cost $(S C)^{1}$} \\
\hline $\mathrm{R} \$ / \mathrm{kg}$ & 0,48 & 0,44 \\
\hline $\mathrm{R} \$ /$ dia & 0,24 & 0,22 \\
\hline \multicolumn{3}{|l|}{$R \$ / d a y$} \\
\hline \multicolumn{3}{|l|}{ Ganho excedente (GE) } \\
\hline \multicolumn{3}{|l|}{ Spare gain $(S G)$} \\
\hline $\mathrm{kg} / \mathrm{dia}$ & 0,175 & 0,212 \\
\hline \multicolumn{3}{|l|}{$\mathrm{kg} / \mathrm{day}$} \\
\hline $\mathrm{R} \$ / \mathrm{dia}^{2}$ & 0,25 & 0,30 \\
\hline \multicolumn{3}{|l|}{$R \$ / d a y^{2}$} \\
\hline $\mathrm{GE} / \mathrm{CS}^{3}$ & 1,04 & 1,36 \\
\hline \multicolumn{3}{|l|}{$S G / S C^{3}$} \\
\hline $\mathrm{GE} / \mathrm{CS}^{4}$ & 1,13 & 1,23 \\
\hline$S G / S C^{4}$ & & \\
\hline
\end{tabular}

${ }^{1}$ Custos de ingredientes $(\mathrm{R} \$ / \mathrm{kg})$ : farelo de soja $-0,58$; farelo de glúten - 0,80; milho em grão-0,24. Fonte: Fábrica de Rações - DZO/UFV (Agosto/2001).

${ }^{2}$ Valor de venda $=\mathrm{R} \$ 42,00 /$ arroba; rendimento de carcaça $=$ $50 \%$.

${ }^{3}$ Estimado com o desempenho individual de cada tratamento.

${ }^{4}$ Estimado com o ganho excedente médio dos tratamentos com suplementação $(0,194 \mathrm{~kg} / \mathrm{dia})$.

1 Ingredient costs $(R \$ / \mathrm{kg})$ : soybean meal - 0,58; corn gluten meal -0,80; corn grain - 0,24. Source: Ration Factory - DZO/UFV (August/2001).

${ }^{2}$ Sale value=R\$42,00/@; carcass dressing $=50 \%$.

${ }^{3}$ Relation was estimated with the individual performance of treatments.

${ }^{4}$ Relation was estimated with the spare mean gain of the supplement treatments $(0,194 \mathrm{~kg} /$ day $)$.

Devido às altas disponibilidades de MS/ha (Tabela 5), durante todo o período experimental, permitindo intensa seleção pelas novilhas, verificouse na forragem consumida, adequada concentração protéica das amostras de extrusa (Tabela 2).

As equações de regressão ajustadas para leitura de $\mathrm{N}-\mathrm{NH}_{3}$ ruminal em função dos tempos para os três suplementos estão expressos na Figura 1.

$\mathrm{Na}$ análise da concentração de amônia ruminal, observaram-se diferenças $(\mathrm{P}<0,05)$ entre suplementos e interação tempo de coleta $\mathrm{x}$ suplemento $(\mathrm{P}<0,05)$. Em virtude disso, efetuaram-se as análises de médias de concentração de amônia de cada tratamento, em função do tempo de coleta, estimando-se as equações de regressão da concentração de amônia para cada tratamento, em função do tempo de coleta (Figura 1).

As concentrações de amônia ruminal dos bovinos submetidos ao tratamento com proteína degradável no rúmen $(\mathrm{MFS}=14,23 \mathrm{mg} / \mathrm{dL})$ foram, em média, 23 
Tabela 5 - Disponibilidade média de matéria seca (MS), em $\mathrm{kg} / \mathrm{ha}$, e coeficientes de variação (CV\%) nos diferentes períodos

Table 5 - Average availability of dry matter (DM), $\mathrm{kg} / \mathrm{ha}$, and coefficient of variation (CV\%) in different periods

\begin{tabular}{lcc}
\hline $\begin{array}{l}\text { Período } \\
\text { Period }\end{array}$ & $\begin{array}{c}\text { Disponibilidade MS (kg/ha) } \\
\text { DM availability }(\mathrm{kg} / \mathrm{ha})\end{array}$ & $\mathrm{CV}(\%)$ \\
\hline 1 & 13199 & 11,04 \\
2 & 15081 & 17,03 \\
3 & 14351 & 17,59 \\
\hline
\end{tabular}

e $30 \%$ superiores às concentrações de amônia dos bovinos nos tratamentos testemunha $(\mathrm{SAL}=11,61 \mathrm{mg} / \mathrm{dL}$ ) e PNDR (MFGM=10,93 mg/dL), respectivamente.

Verificou-se que, em todos os tratamentos, as concentrações de amônia ruminal se mantiveram em níveis acima de $5 \mathrm{mg} / \mathrm{dL}$ (Sater \& Slyter, 1974) e 10 $\mathrm{mg} / \mathrm{dL}$ de líquido ruminal (Leng, 1990), considerados como mínimos para adequada fermentação ruminal da fibra. Entretanto, quando se consideram os valores de concentração de amônia ruminal, preconizados por Leng (1990), $20 \mathrm{mg} / \mathrm{dL}$ de líquido ruminal, como ideais para maximização do consumo voluntário em condições tropicais, verificou-se que, em todos os tratamentos, as concentrações se apresentaram inferiores aos valores sugeridos.

Tabela 6 - Médias das concentração de $\mathrm{N}-\mathrm{NH}_{3}(\mathrm{mg} / \mathrm{dL})$ no líquido ruminal para os diferentes tempos (horas), após o fornecimento do suplemento

Table 6 - Means of $\mathrm{N}-\mathrm{NH}_{3}(\mathrm{mg} / \mathrm{dl})$ concentration at ruminal liquid for differents times (hour), after supplement supply

\begin{tabular}{|c|c|c|c|c|c|}
\hline \multirow[b]{2}{*}{$\begin{array}{l}\text { Suplemento } \\
\text { Supplement }\end{array}$} & \multicolumn{4}{|c|}{$\begin{array}{c}\text { Tempo } \\
\text { Time }\end{array}$} & \multirow[b]{2}{*}{$\begin{array}{l}\text { Média } \\
\text { Mean }\end{array}$} \\
\hline & 0 & 2 & 4 & 6 & \\
\hline $\begin{array}{l}\mathrm{Sal}^{2} \\
\text { Salt }\end{array}$ & $14,9^{\mathrm{A}}$ & $12,1^{\mathrm{A}}$ & $8,9^{\mathrm{B}}$ & $10,4^{\mathrm{A}}$ & 11,6 \\
\hline $\begin{array}{l}\text { MFGM } \\
C M C G\end{array}$ & $10,8^{\mathrm{B}}$ & $7,0^{\mathrm{A}}$ & $13,9^{\mathrm{A}}$ & $12,0^{\mathrm{A}}$ & 10,9 \\
\hline $\begin{array}{l}\text { MFS } \\
C M C S \\
\end{array}$ & $16,2^{\mathrm{A}}$ & $13,7^{\mathrm{A}}$ & $14,8^{\mathrm{A}}$ & $12,1^{\mathrm{A}}$ & 14,2 \\
\hline
\end{tabular}

${ }^{1}$ Médias na coluna, seguidas por letras diferentes, são diferentes $(P<0,05)$ pelo teste de Newman keuls.

2 SAL: mistura mineral.

MFGM: suplemento à base de milho e farelo de glúten de milho; MFS: suplemento à base de milho e farelo de soja;

${ }^{1}$ Means, within a column, followed by different letters are different $(P<.05)$ by Newman Keuls test.

2 Salt: mineral salt.

CMGM: supplement based on corn and corn gluten meal.

CSBM: supplement based on corn and soybean meal.

R. Bras.Zootec., v.31, n.2, p.1052-1058, 2002 (suplemento)
Resultados semelhantes aos deste estudo foram observados por Coomer et al. (1993) e Elizalde et al. (1998), que também verificaram menores concentrações ruminais de amônia, com o fornecimento de suplementos contendo PNDR. As baixas concentrações de amônia ruminal nestes bovinos, possivelmente, devem-se à maior proporção de milho no suplemento MFGM, além de menor quantidade de PDR nestes suplementos, em relação ao suplemento MFS.

Resultados semelhantes ao do presente estudo foram também evidenciados por Chase Jr. \& Hibberd (1987), que reportaram reduções nas concentrações de amônia ruminal, em função do fornecimento de milho. Adicionalmente, os referidos autores relataram que, devido ao fato de a maioria das bactérias celulolíticas requerer amônia para o seu crescimento, baixas concentrações de amônia podem limitar a atividade microbiana e diminuir a taxa e a extensão da digestão da fibra. Posteriormente, os mesmos autores constataram que a amônia ruminal se constituiu como fator limitante na utilização de forragem, salientando, portanto, a importância de se considerarem as diferentes fontes protéicas, na formulação de suplementos. Além disso, devido à baixa degradabilidade ruminal da

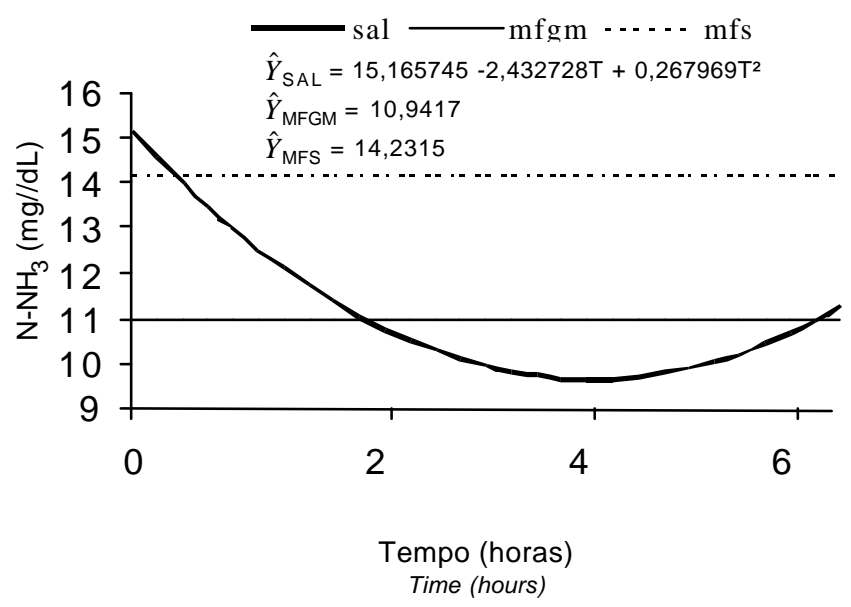

Figura 1 - Estimativas da concentração de nitrogênio amoniacal $\left(\mathrm{N}-\mathrm{NH}_{3}\right)(\mathrm{mg} / \mathrm{dL})$ do líquido ruminal, em função dos tempos $(\mathrm{T})$ de coleta, para cada suplemento.

Figure 1 - Estimate of ammonia nitrogen $\left(\mathrm{N}^{\left.-\mathrm{NH}_{3}\right)}(\mathrm{mg} / \mathrm{dL})\right.$ concentration of ruminal liquid, in function of collecting times, for each supplement. 
proteína do milho, aliada à sua alta proporção na dieta, a quantidade de PDR pode ser limitante para adequado crescimento microbiano, principalmente quando outras fontes de PNDR são fornecidas como suplementos protéicos.

As maiores concentrações ruminais de amônia observadas neste estudo, com o fornecimento do suplemento MFS, concordam com os resultados obtidos por Köster et al. (1996), e refletem o fato de se tratar de uma fonte de nitrogênio prontamente disponível, fator que explica, provavelmente, o melhor desempenho dos animais suplementados com esta fonte.

O presente estudo corrobora os resultados de Karges et al. (1992), os quais ressaltam que a resposta à suplementação com PNDR apenas é provável após os requerimentos de PDR terem sido atendidos.

As equações de regressão ajustadas para as leituras de $\mathrm{pH}$ no líquido ruminal estão expressas na Figura 2.

A análise de $\mathrm{pH}$ ruminal demonstrou efeitos significativos para suplementos $(\mathrm{P}<0,05)$, tempo de coleta $(\mathrm{P}<0,05)$ e interação suplemento e tempo $(\mathrm{P}<0,05)$. Portanto, realizaram-se as análises das médias de $\mathrm{pH}$ ruminal de cada suplemento, dentro de cada tempo (Tabela 7), ajustando-se,

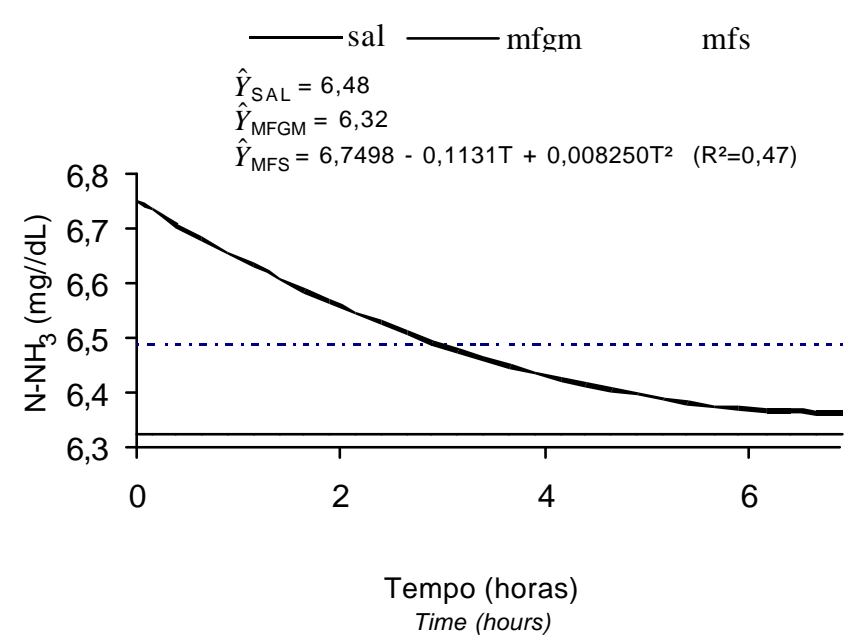

Figura 2 - Estimativa do $\mathrm{pH}$ ruminal, em função dos tempos ( $T$ ) de coleta, para cada suplemento.

Figure 2 - Estimate of ruminal $\mathrm{pH}$, in function of collecting time $(T)$, for each supplement. concomitantemente, equações de regressão para o comportamento do $\mathrm{pH}$ ruminal, em função dos tempos de coleta, para cada suplemento (Figura 2).

$\mathrm{O}$ crescimento das bactérias celulolíticas é retardado quando o $\mathrm{pH}$ é reduzido a níveis inferiores a 6,2 (Orskov, 1982); portanto, efeitos detrimentais sobre a digestão da fibra induzidos por $\mathrm{pH}$ ruminal baixo, devido à suplementação com altos níveis de milho no suplemento MFGM, provavelmente não ocorreram neste estudo, uma vez que os mesmos se mantiveram acima do $\mathrm{pH}$ mínimo sugerido como crítico para adequada atividade celulolítica.

Resultados semelhantes aos deste estudo foram encontrados por Pordomingo et al. (1991), que também não constataram reduções do pH abaixo de 6,2 , bem como efeitos prejudiciais na digestão da fibra induzidos por baixo $\mathrm{pH}$ ruminal, devido à suplementação com milho.

Como pode ser observado na Figura 2, os animais submetidos ao suplemento MFGM exibiram menor $\mathrm{pH}$ ruminal que o dos demais tratamentos, o que, possivelmente, ocorreu em função da maior porcentagem de milho (amido) presente neste suplemento, que, posteriormente, pode ter contribuído para redução no $\mathrm{pH}$ ruminal destes animais.

Tabela 7 - Médias dos valores de pH do líquido ruminal, para os diferentes suplementos, em função do tempo de coleta

Table 7 - Means of $\mathrm{pH}$ values of ruminal liquid for the different supplements, in function of collect time

\begin{tabular}{lccccc}
\hline & \multicolumn{5}{c}{$\begin{array}{c}\text { Tempo } \\
\text { Time }\end{array}$} \\
\cline { 2 - 5 } $\begin{array}{l}\text { Suplemento } \\
\text { Supplement }\end{array}$ & 0 & 2 & 4 & 6 & $\begin{array}{c}\text { Média } \\
\text { Mean }\end{array}$ \\
\hline $\begin{array}{lccccc}\text { Sal } \\
\text { Salt }\end{array}$ & $6,52^{\mathrm{A}}$ & $6,49^{\mathrm{A}}$ & $6,47^{\mathrm{A}}$ & $6,45^{\mathrm{A}}$ & 6,48 \\
MFGM & $6,27^{\mathrm{B}}$ & $6,31^{\mathrm{A}}$ & $6,39^{\mathrm{A}}$ & $6,30^{\mathrm{A}}$ & 6,32 \\
CMCG & $6,75^{\mathrm{A}}$ & $6,54^{\mathrm{A}}$ & $6,44^{\mathrm{A}}$ & $6,36^{\mathrm{A}}$ & 6,52 \\
MFS & & & & & \\
CMCS & & &
\end{tabular}

${ }^{1}$ Médias na coluna, seguidas por letras diferentes, são diferentes $(P<0,05)$ pelo teste de Newman keuls.

2 Sal: mistura mineral.

MFGM: suplemento à base de milho e farelo de glúten de milho.

MFS: suplemento à base de milho e farelo de soja.

${ }^{1}$ Means, within a column, followed by different letters are different $(P<.05)$

by Newman Keuls test.

2 Salt: mineral salt.

CMGM: supplement based on corn and corn gluten meal.

CSBM: supplement based on corn and soybean meal. 


\section{Conclusões}

O uso de suplementos melhorou o desempenho de novilhas mestiças, no período das águas. Dentro do contexto avaliado neste estudo, a relação custo de suplemento/ganho médio diário excedente apontou superioridade para o suplemento constituído por milho e farelo de soja.

Os valores de $\mathrm{pH}$ e a concentração de amônia ruminal foram influenciados pela suplementação e alterados em função dos tempos de coleta, porém mantiveram-se em níveis adequados para digestão e fermentação ruminal da fibra.

\section{Literatura Citada}

ANDRADE, P. Alimentação de bovinos em épocas críticas. In: NUTRIÇÃO DE BOVINOS. CONCEITOS BÁSICOS E APLICADOS, 1993, Piracicaba.Anais...Piracicaba: Fundação de Estudos Agrários Luiz de Queiroz, 1993. p.239-250.

CAMPOS, J. Tabelas para cálculo de rações. Viçosa, MG: Universidade Federal de Viçosa. 2.ed. 1995. 64p.

CHASE JR., C.C.; HIBBERD, C.A. Utilization of low quality native grass hay by beef cows fed increasing quantities of corn grain. Journal of Animal Science, v.65, p.557-566, 1987.

COCHRAN, R.C.; ADAMS, D.C.; WALLACE, J.D. et al. Predicting digestibility of different diets with internal markers: Evaluation of four potential markers. Journal of Animal Science, v.63, n.5, p.1476-1483, 1986.

COOMER, J.C.; AMOS, H.E.; FROETSCHEL, M.A. et al. Effects of supplemental protein source on ruminal fermentation, protein degradation, and amino acid absorption in steers and on growth and feed efficiency in steers and heifers. Journal of Animal Science, v.71, p.3078-3086, 1993.

ELIZALDE, J.C.; CREMIN, J.D.; FAULKNER, D.B. et al. Performance and digestion by steers grazing tall fescue and supplement with energy and protein. Journal of Animal Science, v.76, p.1691-1701, 1998.

HAFLEY, J.L.; ANDERSON, B.E.; KLOPFENSTEIN, T.J. Supplementation of growing cattle grazing warm-season grass with proteins of various ruminal degradabilities. Journal of Animal Science, v.71, p.522-529, 1993.

KARGES, K.K.; KLOPFENSTEIN, T.J.; WILKERSON, V.A. et al. Effects of ruminally degradable and escape protein supplements on steers grazing summer native range.Journal of Animal Science, v.70, p.1957-1964, 1992.

KÖESTER, H.H.; COCHRAN, R.C.; TITGEMEYER, E.S. et al. Effect of increasing degradable intake protein on intake and digestion of low-quality, Tallgrass-Prarie forage by beef cows. Journal of Animal Science, v.74, p.2473-2481, 1996.

LENG, R.A. Factors affecting the utilization of "poor-quality" forages by ruminants particularly under tropical conditions. Nutrition Research Review, v.3, p.277-303, 1990.

McMENIMAN, N.P. Methods of estimating intake of grazing animals. In: REUNIÃO ANUAL DA SOCIEDADE BRASILEIRA DEZOOTECNIA, 34., 1997, Juiz de Fora. Anais... Juiz de Fora: Sociedade Brasileira de Zootecnia, 1997. p.131-168.
NATIONAL RESEARCH COUNCIL - NRC. Nutrient requirements of dairy cattle. 6.ed. Washington, D.C.: Academic Press, 1989. 158p.

ORSKOV, E.R. Protein nutrition in ruminants. New York: Academic Press, 1982. 178p.

PAULINO, M.F. Suplementos múltiplos para recria e engorda de bovinos em pastagens. In: CONGRESSO NACIONAL DOS ESTUDANTES DEZOOTECNIA, 1998, Viçosa, MG. Anais... Viçosa, MG: Associação Mineira dos Estudantes de Zootecnia, 1998. p.173-188.

PEIXOTO, A.M. Níveis nutricionais para alta produção de carne. In: NUTRIÇÃO DE BOVINOS. CONCEITOS BÁSICOS E APLICADOS. Piracicaba, 1993. Anais... Piracicaba: Fundação de Estudos Agrários Luiz de Queiroz, 1993. p.167-198.

PENNING, P.D.; JOHNSON, R.H. The use of internal markers to estimate herbage digestibility and intake. 2. Indigestible acid detergent fiber. Journal of Agricultural Science, v.100, n.1, p.133-138, 1983.

POPPI, D.P.; McLENNAN, S.R. Protein and energy utilization by ruminants at pasture. Journal of Animal Science, v.73, p.278-290, 1995.

PORDOMINGO, A.J.; WALLACE, J.D.; FREEMAN, A.S. et al. Supplemental corn grain for steers grazing native rangeland during summer. Journal of Animal Science, v.69, p.1678-1687, 1991.

REIS, R.A.; RODRIGUES, L.R.A.; PEREIRA, J.R.A. A suplementação como estratégia de manejo de pastagem. In: SIMPÓSIO SOBRE MANEJO DE PASTAGEM, 13., 1996, Piracicaba. Anais... Piracicaba: Fundação de Estudos Agrários Luiz de Queiroz, 1997. p.123-151.

SANCHES, L.T.T.; NASCIMENTO Jr.; D., DIOGO, J.M.S. et al. Composição química da forragem disponível versus dieta de bovinos em pastagem natural. Revista Brasileira de Zootecnia, v.22, n.5, p.852-861, 1993.

SATTER, L.D.; SLYTER, L.L. Effect of ammonia concentration on rumen microbial protein production in vitro. British Journal Nutrition, v.32, p.199, 1974.

SILVA, D.J. Análise de alimentos: métodos químicos e biológicos. Viçosa, MG: Universidade Federal de Viçosa, 1990. 165p.

SNIFFEN, C.J.; O'CONNOR, J.D.; Van SOEST, P.J. et al. A net carbohydrate and protein sytem for evaluating cattle diets: II - Carbohydrate and protein availability.Journal of Animal Science, v.70, p.3562-3577, 1992.

UNIVERSIDADE FEDERAL DE VIÇOSA- UFV. SAEG-Sistema de análises estatísticas e genética. Viçosa, MG, 1995.

Van SOEST, P.J.; ROBERTSON, J.B.; LEWIS, B.A. Methods for dietary fiber, and nonstarch polysaccharides in relation to animal nutrition. Journal of Dairy Science, v.74, n.10, p.3583-3597, 1991.

VILLARES, J.B. Zebu e produtividade de bovinos nos trópicos. In: REUNIÃO ANUAL DA SOCIEDADE BRASILEIRA DE ZOOTECNIA, 21., Belo Horizonte, 1984.Anais... Belo Horizonte: Sociedade Brasileira de Zootecnia, 1984. 76p.

WILLIANS, C.H.; DAVID, D.J.; IISMA, O. The determination of chromic oxide in faeces samples by atomic absorption spectrophotometry. Journal of Agricultural Science, v.59, p.381-385, 1962.
Recebido em: 20/06/01

Aceito em: 17/01/02 